\title{
Posttraumatic Epilepsy among Epileptic Children Seen in a Pediatric Neurology Clinic in Enugu, Nigeria-A Descriptive Study
}

Ngozi Chinyelu Ojinnaka*, Mkpouto Udeme Akpan and Ann Ebele Aronu

Department of Pediatrics, University of Nigeria Nsukka Enugu, Nigeria

"Corresponding author: Ngozi Chinyelu Ojinnaka, University of Nigeria Nsukka Enugu, Nigeria, Tel: +234-8030965131; E-mail: ngojimed@yahoo.com Rec Date: Nov 30, 2015; Acc date: Feb 18, 2016; Pub Date: Feb 25, 2016

Copyright: (c) 2016 Ojinnaka NC, et al. This is an open-access article distributed under the terms of the Creative Commons Attribution License, which permits unrestricted use, distribution, and reproduction in any medium, provided the original author and source are credited.

\begin{abstract}
Background: There is a wide variation in epidemiology and clinical profile of children with seizures following a head injury. Head injury can result from a variety of trauma to the head and remains a worldwide public health problem.

Purpose: To determine the prevalence and characteristics of posttraumatic epilepsy among epileptic children seen in a pediatric neurology clinic in Enugu, Nigeria.

Method: Records of epileptic patients who presented from January 2009 to January 2013 were reviewed. Data of those with history of head injury prior to onset of the seizure were documented. Statistical analysis was done using SPSS. Frequency and contingency table were derived and $\mathrm{Chi}^{2}$ test was used for associations.

Result: Out of 1400 patients, who presented to the clinic, six hundred and eighty-two (48.7\%) patients had epilepsy and fifty-nine of the epileptics $(8.65 \%)$ had history of significant head injury before the onset of seizure. The peak incidence was in the preschool age (13-60 months). Falls from heights were the commonest mechanism of head injury. Mild, moderate and severe trauma was documented in 32, 19 and 8 patients respectively. Majority of patients with severe trauma fell from heights. There was however no statistically significant difference between the mechanism of head injury and degree of severity of trauma $(p=0.73)$. Complex partial seizure was the most common type. Seizure control was documented in 35 patients who were followed up for 18 months or more. Eighteen patients $(51.43 \%)$ had good control.
\end{abstract}

Conclusion: Head injury is a significant cause of epilepsy in this environment. Home injuries may have farreaching public health concern in our environment.

Keywords: Posttraumatic seizure; Epilepsy; Head injury; Anticonvulsant; Environment

\section{Introduction}

Epilepsy is a well-recognized, though uncommon, complication of traumatic brain injury in children [1]. Post-traumatic seizures account for $20 \%$ of all symptomatic epilepsies [2]. A prevalence of $15.57 \%$ has been reported from an adult clinic in Benin City, Nigeria [3]. Seizures may develop immediately after an injury to the brain or may be delayed, manifesting months or yrs. after the initial trauma. Though the risk of Post-Traumatic Epilepsy (PTE) is related to the severity of the injury, trivial head injury resulting in mild to moderate trauma can result in seizures [4]. Head injury can result from a variety of trauma to the head and remains a public health problem worldwide. It is documented that Traumatic Brain Injury (TBI) is responsible for about a third (30.5\%) of all injury-related deaths in the United States. In Nigeria, it is the most common cause of trauma-related death in childhood [5]. Seizures can develop at any time following head injury. Those that occur during the 1 st week of the trauma ( $\geq 12 \mathrm{hrs}$. to 7 day) are known as early post-traumatic seizures and are more common in children than adults with an incidence of about $5 \%-20 \%$ in children [6]. Any seizure that occurs after this period is called late-onset posttraumatic seizure. Presence of more than one unprovoked late- onset seizure after a head injury is recognized as posttraumatic epilepsy. Estimates of prevalence of posttraumatic epilepsy in children have varied considerably, probably because of differences in the populations studied. In the developing countries, due to limited neurodiagnostic facilities and poor utilization of health facilities, it is not easy to document the true prevalence of Post-Traumatic Epilepsy (PTE). In an environment with various forms of physical hazards, it is important to note the prevalence and clinical features of PTE in children. This study was undertaken to determine the prevalence of posttraumatic epilepsy in a pediatric neurology clinic in Enugu, Nigeria and identify factors associated with seizure pattern and control.

\section{Materials and Method}

Records of children who presented at the Pediatric Neurology Clinic of University of Nigeria Teaching Hospital, Enugu from January 2009 to January 2013 were reviewed. Patients with history of a head injury and more than one episode of late-onset unprovoked seizure not attributed to any other cause were identified. Patients who had one or more episodes of seizure before the trauma, or any other chronic neurological disorder were excluded. 
There were two dependent variable i) seizure pattern characterized as partial (complex and simple, generalized (atypical absence, myoclonic and GTC) or mixed and seizure control.

Independent variables of interest were age of child at time of trauma, gender, and parents' socioeconomic status, age of onset of seizure, frequency of seizure before presentation, presence of deficit, medication (monotherapy and polytherapy), cause, type and severity of trauma. Findings on physical examination carried out on all the patients with emphasis on the central nervous system were documented. Reports of any neurodiagnostic investigations such as Electroencephalography (EEG), Skull X-ray and CT scan carried out on the patients were recorded.

Severity of trauma was classified as mild (absence of fracture with loss of consciousness or post-traumatic amnesia for less than $30 \mathrm{mins}$ ), moderate (loss of consciousness or post-traumatic amnesia lasting for $30 \mathrm{mins}$ to $24 \mathrm{hrs}$. or a skull fracture) and severe (brain contusion or loss of consciousness or post-traumatic amnesia more than $24 \mathrm{hrs}$.) [7].

The socio-economic status of the children was derived using the occupational and educational levels of parents as classified by Oyedeji [8] and subjects were classified into five Grades [1-5] based on the occupational and educational levels of parents. This was further grouped into upper [1,2], middle [3] and lower [4,5] classes.

Drug therapy commenced on presentation and patients' response to treatment was recorded. Seizure control was assessed in patients who were on follow up for up to 18 months or more this was because a minimum of one year of follow-up was required for proper assessment of drug treatment and seizure control. Seizure control as proposed by Iloeje was modified and graded according to reduction of seizure frequency when compared to frequency at presentation $[9,10]$. Response to therapy by patient was assessed during each visit and rate of reduction in seizure frequency classified as poor $(<50 \%)$, fair (50 to $70 \%$ ), fairly good ( 71 to $<100 \%$ reduction) and good ( $100 \%$ reduction) since commencement of therapy. Ethical clearance was obtained before commencement of the study.

Descriptive statistics were conducted. Contingency tables were derived using Chi2 test or Fisher's exact test as appropriate. P values of $<0.05$ were considered statistically significant. Statistical analyses were done using SPSS version 20.

\section{Results}

A total of 1400 patients presented to the Paediatric Neurology Clinic of the hospital during the period of study. Six hundred and eighty- two ( $48.7 \%$ of the total) patients who presented to the clinic had epilepsy and fifty-nine (8.65\%) had posttraumatic epilepsy.

Table 1 shows descriptive characteristics of the study population. The age ranged from 3weeks to 16yrs with a mean age (SD) of 58.1 ( \pm 50.22) months at the time of trauma. The peak incidence was in the pre-school age (13-60 months). There were 33 (56\%) males and 26 (44\%) females. A total of twenty-four patients $(40.7 \%)$ were in middle socio-economic class. There was history of loss of consciousness following the injury in 27 (45.8\%) subjects with duration of loss of consciousness ranging from less than 5 mins to 6 months. It was also reported that 2 patients had distorted speech and amnesia immediately after the fall which lasted for about 24 hrs while 3 had motor deficits namely transient paresis of an upper limb in 2 patients and hemiplegia which was still present at presentation in one. Only 10 patients had a
CT scan. Subdural hematoma was diagnosed in 3 of the patients while the scan was normal in the other patients. Result of skull X-ray was documented in 50 patients. One patient had a depressed fracture requiring surgical intervention while 5 patients had linear fractures.

\begin{tabular}{|l|l|l|l|l|}
\hline \multirow{2}{*}{$\begin{array}{l}\text { Age range at } \\
\text { timeof trauma } \\
\text { (months) }\end{array}$} & \multicolumn{4}{|l|}{ Socio-economic class } \\
\cline { 2 - 5 } & Upper & middle & lower & Total (\%) \\
\hline$<7$ & 1 & 5 & 1 & $7(11.9)$ \\
\hline $12-J u l$ & 1 & 1 & 2 & $4(6.8)$ \\
\hline $13-60$ & 8 & 9 & 4 & $21(35.6)$ \\
\hline $61-120$ & 1 & 7 & 9 & $17(28.8)$ \\
\hline$>120$ & 2 & 2 & 6 & $10(16.9)$ \\
\hline Total & 13 & 24 & 22 & $59(100)$ \\
\hline$x^{2}=13.03 P=0.11$ & & & \\
\hline
\end{tabular}

Table 1: Descriptive stastistics of study population $(n=59)$.

Table 2 shows the causes of head injury and severity of trauma in the subjects. Majority (62.8\%) of the patients fell from heights for example, storey- buildings, tall trees (mango and cashew trees) and various other heights such as bookshelf up to $1.5 \mathrm{mts}$ high, arms and back of caregivers. All the patients had blunt head injury. Using the classification of severity of trauma, 32 patients $(54.2 \%)$ had mild trauma while $19(32.2 \%)$ and $8(13.6 \%)$ had moderate and severe trauma respectively. Severe trauma was documented in 7 patients that fell from heights and one that had road traffic accident. There was however no statistically significant difference between the causes of head injury and severity of trauma $\left(\chi^{2}=5.3, p=0.73\right)$.

\begin{tabular}{|l|l|l|l|l|}
\hline \multicolumn{5}{|c|}{ Degree of Severity } \\
\hline Cause of injury & Mild & Moderate & Severe & Total \\
\hline $\begin{array}{l}\text { Fall from height }> \\
1.5 \mathrm{mts})\end{array}$ & $4(6.7)$ & $9(15.2)$ & $7(11.9)$ & $20(33.8)$ \\
\hline $\begin{array}{l}\text { Fall from height } \\
\text { ( } 1.5 \mathrm{mts})\end{array}$ & $14(23.7)$ & $3(5.1)$ & - & $17(28.8)$ \\
\hline $\begin{array}{l}\text { Hit head against } \\
\text { object }\end{array}$ & $5(8.5)$ & $2(3.4)$ & & $7(11.9)$ \\
\hline $\begin{array}{l}\text { Slipped while } \\
\text { running }\end{array}$ & $5(8.5)$ & $2(3.4)$ & - & $7(11.9)$ \\
\hline $\begin{array}{l}\text { Falling object hit } \\
\text { the head }\end{array}$ & $3(5.1)$ & $2(3.4)$ & - & $5(8.5)$ \\
\hline $\begin{array}{l}\text { Road Traffic } \\
\text { Accident }\end{array}$ & $1(1.7)$ & $1(1.7)$ & $1(1.7)$ & $3(5.1)$ \\
\hline Total & $32(54.2)$ & $19(32.2)$ & $8(13.6)$ & $59(100)$ \\
\hline
\end{tabular}

Table 2: Causes of head injury and severity of trauma.

Seizure-related variables in the patients are shown in Table 3.

\begin{tabular}{|l|l|l|}
\hline Variables & No. of patients & Percentage \\
\hline History of early-onset seizure & 12 & 20.3 \\
\hline
\end{tabular}


Page 3 of 5

\begin{tabular}{|c|c|c|}
\hline \multicolumn{3}{|l|}{ Time of onset of PTS } \\
\hline$<6$ & 32 & 45.5 \\
\hline 42533 & 8 & 11.8 \\
\hline $13-18$ & 9 & 8.5 \\
\hline $19-24$ & 5 & 5.4 \\
\hline$>24$ & 5 & 8.5 \\
\hline \multicolumn{3}{|l|}{ Seizure type } \\
\hline CPS with or without $2^{\circ}$ gen. & 22 & 37.3 \\
\hline GTC & 18 & 30.5 \\
\hline Mixed & 10 & 16.9 \\
\hline Myoclonic drops + Atypical absence & 7 & 11.9 \\
\hline Simple Partial & 2 & 3.4 \\
\hline \multicolumn{3}{|l|}{ No. of fits before presentation } \\
\hline$<6$ & 15 & 25.4 \\
\hline 42531 & 11 & 18.6 \\
\hline$>10$ & 33 & 56 \\
\hline \multicolumn{3}{|l|}{ Presence of Status epilepticus } \\
\hline Yes & 26 & 44 \\
\hline No & 33 & 56 \\
\hline \multicolumn{3}{|l|}{ Family history of seizure } \\
\hline Yes & 14 & 23.7 \\
\hline No & 45 & 76.3 \\
\hline \multicolumn{3}{|l|}{ EEG result } \\
\hline Abnormal & 39 & 66.1 \\
\hline Normal & 9 & 15.3 \\
\hline No result & 11 & 18.6 \\
\hline
\end{tabular}

Table 3: Seizure-related variables in the patients.

Twelve (20.3\%) out of 59 patients previously had early-onset seizure. Nine $(15.3 \%)$ and one $(1.7 \%)$ of the 12 patients had mild and severe trauma respectively. Seizures occurred after 24 months in $5(8.5 \%)$ patients. Complex partial seizures with or without secondary generalization occurred in 22 patients $(37.3 \%)$ while Generalized Tonic-Clonic seizure (GTC) occurred in 18 patients (30.5\%). No patient had simple absence seizure.

Thirty-three patients (56\%) had more than 10 episodes of seizure attacks before presentation and $26(44 \%)$ have had one or more episodes of status epilepticus as at the time of the study. There was a positive family history of seizure in 14 (23.7\%) patients. Electroencephalograph (EEG) was obtained in 48 patients while 11 patients $(18.6 \%)$ had none due to financial constraints. Thirty-nine patients $(66.1 \%)$ had abnormal EEG records. Seven of these patients showed focal high amplitude spikes and sharp discharges, while 5

patients had a similar pattern with rapid generalization. Eleven patients had generalized high amplitude spike and sharp waves.

Seizure control was documented in 35 patients who were followed up for 18 months or more. Duration of follow up of these 35 patients ranged from 18 months to 5 yrs. Twenty-seven patients (77.1\%) were on monotherapy throughout the period of follow up while 8 patients (22.9\%) were on polytherapy. On the whole, eighteen patients (51.43\%) had good seizure control while fair or poor control was noted in 5 patients each. Twenty of the patients on monotherapy were managed with carbamazepine alone while 5 patients were on phenytoin. The remaining two were controlled with phenobarbitone. Seizure control was good in 11patients. Among the 10 patients with fair and poor control, 6 fell from heights ( $>4 \mathrm{ft}$ high), one patient was hit by a falling object while one was involved in a road traffic accident. Degree of severity was mild in 8 patients and severe in the remaining 2 patients. No patient with normal tracing had a poor control. There was an association between the EEG results and seizure control with $\chi^{2}=15.5$ and $P=0.004$. There was also an association between the severity of trauma and seizure control $\left(\chi^{2}=6.46\right.$ and $\left.p=0.03\right)$.

\section{Discussion}

In this study, 59 epileptic patients (8.5\%) had a history of traumatic brain injury prior to onset of seizure. It is known that posttraumatic epilepsy accounts for $4-15 \%$ of all cases of epilepsy and this depends on the demographics of the population studied, the severity of the injury and length of follow-up after the injury $[3,11]$.

The peak age incidence at the time of trauma was the pre-school period with a preponderance of males, and majority of the patients was from the low socio-economic class. This agrees with previous report from this country [12-14]. Oluwole [13] noted that being hit by a motor vehicle or motor bike was the commonest cause of traumatic brain injury for subjects $\leq 12$ yrs of age. Male preponderance has also been documented with the highest rate occurring among the lowest socioeconomic classes [13]. Most trauma resulting from domestic injuries occur during the pre-school period [15].

The pattern of mechanism of head injury in this study shows that falls from heights more than $1.5 \mathrm{mts}$ high were the highest cause of head injury in children. Trees and buildings are common heights in our environment. Tree climbing has been identified as a common hazard in our environment and children climb economic trees such as mango and cashew trees during the fruiting season [15]. In UK, $20 \%$ of patients admitted after traumatic head injury have been involved in a Road Traffic Accident (RTA) and this more frequently results in deaths [4]. Others result from falls and assaults that are often, especially in younger persons, alcohol-related. Domestic injuries are not commonly reported as mechanism of traumatic brain injury in developed countries as in the developing countries. Mechanism of trauma in majority of the patients in this study was as a result of such injuries. These include falls from different heights within the home, accidental hits on the head (either by/or against object) and slipping off while running. Pedal cycle for recreation accounts for many injuries, including head injury, in children especially in the developed countries [7]. None of our patients had head injury from pedal cycle. Such recreational activity is not common in our environment.

Mild head trauma was noted in $54.2 \%$ of patients in the study while moderate and severe head trauma was documented in $32.2 \%$ and $13.6 \%$ respectively. Due to late presentation and ill-equipped neurosurgical units with lack of proper neuro-diagnostic facilities for 
surgical interventions in our environment, many patients with head injury especially the severe form do not survive. Annerger et al. [7] noted a moderate but not significant excess of seizures after mild traumatic brain injuries with an excess risk of 1.5 and the risk continued to be elevated for 5 yrs. It is also known that children can develop seizure with the mildest form of injury. Hawley et al. [16] noted that a significant proportion of children with mild head injury were found to have moderate neurological disability at follow up. This has been attributed to the unique biophysical properties of the child's skull and brain.

Twelve patients (20.3\%) had a history of early-onset seizure (fits within one week of injury). Early seizure has been noted to occur more commonly in children than adults and can occur in up to $50 \%$ of patients depending on severity of brain injury. This likely supports the non -predictive response of children to head injury reported by some authors [14,17]. However it is possible that some of the studies reporting higher rates of early seizures may have included patients with immediate seizures (seizures occurring within $24 \mathrm{hrs}$ of the trauma). Chiaretti et al. [17] noted that 10 of the 15 children with early seizures in their study had experienced their seizures "within the first $24 \mathrm{hrs}$ ". Such seizures are not regarded as early seizures and therefore were not included as such in this study. Six patients (10.1\%) had a recurrence within 12 months after the first fit. Onset of seizures within the first week is associated with a higher likelihood of seizure recurrence. Approximately $50-60 \%$ of patients experiencing early fits will have seizures recurring within 12 months [2]. In this study, 5 patients (14.3\%) developed the first seizure 2 yrs or more after trauma and these fell from various forms of heights. It is well documented that some patients with post-traumatic epilepsy had their first seizure $5 \mathrm{yrs}$ or more after the head trauma $[6,18]$. Annegars et al. [7] in their large cohort study noted that brain contusion and subdural haematoma were the strongest risk factors for late seizures, and the increased risk of seizures in such patients persists for at least 20yrs. Skull fractures and prolonged loss of consciousness were also significant though weaker predictors of late-onset seizures. One patient with loss of consciousness for about 6 months following a fall from two storey building developed seizures 9 yrs later. Szabo [19] reported a case example of a 17 year old boy who had a head injury at age 10 months and developed features suggestive of complex partial seizures during adolescence. He was successfully managed with carbamazepine. Emanuelson and Uvebrant [20] in a population-based study reported on the occurance of epilepsy during the first 10yrs after traumatic brain injury acquired in childhood. They noted that traumatic brain injury is a relatively rare cause of epilepsy in childhood. However immediate seizures are associated with an increased risk of developing posttraumatic epilepsy. Patients with other causes of trauma developed their first seizure within the first year of trauma. The reason for this is not clear. Complex Partial Seizure (CPS) with or without secondary generalization was most common type of seizure following trauma in our children. Complex partial seizures commonly follow definite brain lesions. Reports on seizure pattern following trauma, however, have been contradictory. Appleton and Demellweek [1] noted CPS in all 9 patients with seizure in their study and $66.7 \%$ had CPS with secondary generalization. Prokhorova [18] in her study of 78 patients aged from 3 to 14 yrs noted that the latent period of PTE in children is largely dependent on child's age at the time of brain injury than on its severity. Moreover, each age group was characterized by certain types of epileptic attacks: polymorphic seizures with predominance of primarygeneralized ones prevailed in the younger age-group children (3-6 yrs), secondary-generalized seizures occurred in $52.2 \%$ of children in the middle age-group (7-10 yrs), and partial seizures appeared in the older age-group (63.3\%). However without a close observation and possibly EEG backing, CPS with secondary generalization is often misinterpreted as generalized seizure.

Seventy-one percent of the children had good seizure control with twenty-seven patients still on monotherapy (mainly carbamazepine) with good drug compliance at the time of the study. Carbamazepine and phenytoin have been found to be very effective in management of posttraumatic seizure in our environment $[3,6]$. Carbamazepine has also remained an effective anti-epileptic drug especially in CPS with or without secondary generalization [19,21]. With adequate drug compliance and ability to procure the first line drugs for adequate seizure control, good control was achieved in majority of the patients.

\section{Conclusion}

Prevalence of traumatic brain injury among children with epilepsy in this study corroborates with reports from other authors. Type and cause of trauma vary widely from what is reported in the developed countries. Most of the patients in this study had mild head injury. There is need for a proper follow up of any child with head injury irrespective of the severity of the injury. There is also need for a prospective study on children with head injury in our environment since a follow-up from the time of injury to onset of seizure in a longitudinal study would have been most adequate. The results from this work serve as basis for providing health education on injury prevention to reduce possible long term sequelae associated with pediatric head injury.

\section{Study Limitation}

Most of these patients did not present to our hospital at the time of the trauma. Early presentation would have enabled a thorough assessment of the patients at time of injury and proper follow up. Also access to neurodiagnostic facilities is limited due to paucity of neurodiagnostic equipments such as CT scan and MRI. Even when available, most patients cannot afford the cost of the investigation. This explains the low number that had a CT scan. Finally due to small sample size, we report only a descriptive analysis of our study. Further analysis with statistical tools such as regression analysis will need a larger sample size.

\section{References}

1. Appleton RE, Demellweek C (2002) Post-traumatic epilepsy in children requiring impatient rehabilitation following head injury. J Neurol Neurosurg Psychiatry 72: 669-672.

2. Angeleri F, Majkowski J, Cacchio G (1999) Post- epilepsy risk factors one year prospective study after head injury. Epilepsia 40: 1222-1230.

3. Ogunrin OA, Adeyekun AA (2010) Profile of post-traumatic epilepsy in Benin City, Nigeria. West Afr J Med 29: 153-157.

4. Krauss T, Meyer L, Devinsky O (1996) Epilepsy after a minor head injury. J Epilepsy 9: 94-97.

5. Faul M, Xu L, Wald MM, Coronado VG (2010) Traumatic brain injury in the United States: emergency department visits, hospitalizations, and deaths. Atlanta (GA): Centers for Disease Control and Prevention, National Center for Injury Prevention and Control.

6. Odebode OT, Sanya EO (2008) Outcome of early posttraumatic seizure: an experience in Nigeria. Nigerian J Clinical Practice 11: 193-198.

7. Annegers JF, Hauser WA, Coan SP, Rocca WA (1998) A population-based study of seizures after traumatic brain injuries. N Engl J Med 338: 20-24. 
Citation: Ojinnaka NC, Akpan MU, Aronu AE (2016) Posttraumatic Epilepsy among Epileptic Children Seen in a Pediatric Neurology Clinic in Enugu, Nigeria-A Descriptive Study. J Epilepsy 2: 105. doi:10.4172/elj.1000105

Page 5 of 5

8. Oyedeji G (1985) Social-economic and cultural background of hospitalized children in Ilesha. Nigerian J Paediatr 12: 111-117.

9. Wang HC, Chang WN, Chang HW, Ho JT, Yang TM, et al.(2008) Factors predictive of outcome in posttraumatic seizures. J Trauma 64: 883-888.

10. Iloeje SO (1989) The pattern of childhood epilepsy with mental retardation in Nigeria. Journal of Tropical Paediatrics 35:163-168.

11. Billingham JR (1970) Epilepsy Challenged 15 mnths's experience in the NeurologicalClinic Mulago Hospital Kampala. East Afr Med J 47: 288.

12. Suresh HS, Praharaj SS, Indira DB, Shukla D, Sastry KVR (2003) Prognosis in children with head injury: an analysis of 340 patients. Neurol India 51:16-18.

13. Oluwole OSA (2011) Incidence and Risk Factors of Early Post-traumatic seizures in Nigerians. Brain Injury 25: 980-988.

14. Asindi AA, Efem SEE, Onuba O, Asuquo ME (1986) Accidental Trauma in Children. Nig J Paediatr 13: 77-81.

15. Ohaegbulam SC (1978) Analysis of 1089 cases of head injury. Afr J Med Sci 7: 23-27.
16. Hawley CA, Ward AB, Magnay AR, Long J (2004) Outcome following childhood head injury: a population study. J Neurol Neurosurg Psychiatry 75: 737-742.

17. Chiaretti A, Benedictis RD, Polidori G, Piastra M, Iannella A, et al. (2000) Early post-traumatic seizures in children with head injury. Childs Nerv Syst 16: 862-866.

18. Prokhorova A (2011) Clinical features of posttraumatic epilepsy in children. Medical and Health Science J 7: 69-74.

19. Szabo CP (1999) Complex partial seizure in adolescent psychiatric inpatient setting. J Am Acad Child Adolesc Psychiatry 38: 60-64.

20. Emanuelson I, Uvebrant P (2009) Occurrence of epilepsy during the first 10 yrs after traumatic brain injury acquired in childhood up to the age of 18 yrs in the south western Swedish population-based series. Brain Inj 23: 612-216.

21. Barry E (2001) Posttraumatic epilepsy In: The treatment of epilepsy: Principles and practice. (3rdedn), Philadelphia, pp: 6039-6061. 